\title{
Rapid identification of antimicrobial resistance patterns allows a faster antibiotic adequacy
}

\author{
Adrian Ceccato ${ }^{1,2}$, Otavio T. Ranzani ${ }^{1,3}$ and Antoni Torres ${ }^{1 *}$ \\ See related research by Garnier et al., https://ccforum.biomedcentral.com/articles/10.1186/s13054-017-1746-6
}

Keywords: Antimicrobial resistance, Diagnosis, Intensive care unit

Antimicrobial resistance is an important problem that requires an urgent response from the scientific community [1]. One of the main goals is to develop new molecules and antibiotics able to cover extended and pan-resistant strains. However, strategies are also needed to prevent the development of new resistant strains. The concept of antibiotic stewardship addresses this situation by seeking to increase appropriate antibiotic coverage and to reduce the unnecessary use of antibiotics [2, 3].

Early, appropriate empirical treatment is associated with better survival [4]. Furthermore, if the initial antibiotic treatment is subsequently modified in the light of the culture results, the patient's outcome does not seem to be affected [5]. Many strategies for improving adequate empirical treatment coverage and for limiting the use of empirical broad-spectrum antibiotics have been developed, such as the use of risk factors or scores to identify patients who are particularly vulnerable to multidrugresistant germs [6]. The main problem is that these strategies lack external validation and usually have poor predictive performance; they may encourage the overuse of antibiotics or, more importantly, may not improve the appropriate treatment rate [7, 8].

The use of techniques for the rapid etiologic diagnosis of germs and their resistance patterns seems to be the most promising strategy for achieving targeted, fast, appropriate initial treatment and for limiting unnecessary antibiotic use [9]. Various techniques have been developed

\footnotetext{
*Correspondence: atorres@ub.edu

${ }^{1}$ Department of Pneumology, Institut Clinic de Respiratori, Hospital Clinic of Barcelona - Institut d'Investigacions Biomèdiques August Pi i Sunyer (IDIBAPS), University of Barcelona (UB) - SGR 911 - Ciber de Enfermedades Respiratorias (Ciberes, CB06/06/0028), Villarroel 170, 08036 Barcelona, Spain Full list of author information is available at the end of the article
}

for this purpose. Polymerase chain reaction (PCR)-based techniques can be performed directly in fresh samples such as respiratory samples (sputum, tracheal aspirate, or nasopharyngeal swab) and blood. These methods can provide valuable information for clinicians aiming to identify a pathogen or looking specifically for a resistant "signature", or both. They can also establish whether the etiology is fungal or viral. Several other techniques have been tested for fast identification of germs and resistant patterns, such as MALDI-TOF, Finger Print, LAMP, and chromogenic-based methods [10].

In a case-control study, Garnier and coworkers evaluated the usefulness of betaLACTA ${ }^{\circ}$ in critically ill patients [11]. BetaLACTA ${ }^{\oplus}$ is a specific new chromogenic device for diagnosing third-generation cephalosporin-resistant Gram-negative bacilli (extended-spectrum beta-lactamase, carbapenemase-, or acquired AmpC-producing Enterobacteriaceae species) and must be performed on isolated strains. Controls were patients enrolled prior to the implementation of the technique. The authors found that cases had earlier antibiotic adaptation (43\% vs $2 \%, p<0.01)$, which shortened the time to escalation in cases of inappropriate empirical treatment $(50.5(48-73)$ to 27 $(24-28) \mathrm{h}, p<0.01)$ and increased antibiotic adequacy (98\% vs. $77 \%, p<0.01)$. Regarding the resistance detection, only one false-negative was observed. In previous reports, betaLACTA ${ }^{\oplus}$ showed a lower sensitivity for AmpC-overproducing Enterobacteriaceae detection than for extended-spectrum beta-lactamases [11].

Among the main advantages of this device are its costeffectiveness, the fact that the results can be assessed after few minutes, and the fact that no special equipment is required. Nevertheless, Garnier's study has 
several limitations, in addition to the study design chosen. The selection of historic controls may have introduced a bias, given the changes in the local flora, in empiric antibiotic use protocols, and in clinicians' behavior over the years with regard to escalating/de-escalating antibiotics.

The performance of the device has been validated in various studies. One of the main strengths of the study by Garnier et al. was to assess not just the device accuracy but also its impact in clinical practice [11]. Interestingly, the local staff appeared to implement the new technology in their clinical practice relatively fast. It is possible that this "early adopter" profile favored the observation of the clinical impact. Another strength is the fact that the authors searched for a specific resistant mechanism instead of looking for a range of pathogens and resistance patterns. Indeed, this target testing might be more feasible and improve clinicians' reliability [11].

Other devices for rapid etiologic diagnosis of infection are also available [10]. There are several reports on the use of devices in blood samples in general patients with sepsis, though their performance is only low to moderate and further improvements are necessary [12]. Other clinical studies for rapid diagnosis in community- or hospital-acquired pneumonias have shown better performance than blood samples, mainly because of the inherent differences between blood and respiratory samples $[9,13,14]$. However, one of the main difficulties for clinicians using rapid diagnostic methods in respiratory samples is to differentiate infection from colonization, and to assess the presence of viable bacteria. Other adjunctive methods or biomarkers can help to improve the discriminatory capacity.

Future research should validate this new diagnostic technique through prospective studies and randomized clinical trials. These studies should evaluate not just its accuracy, but also its net benefits and its impact in reducing the use of broad-spectrum antibiotics, the occurrence of adverse events, and the emergence of new resistances, followed by a cost-effective analysis.

\section{Acknowledgements}

Not applicable.

Funding

AC and OTR are recipients of an ERS long-term fellowship.

Availability of data and materials

Not applicable.

\section{Authors' contributions}

Drafting of the manuscript: $A C, O R, A T$; critical revision of the manuscript for important intellectual content: AC, OR, AT. All authors read and approved the final manuscript.

Authors' information

Not applicable.

Ethics approval and consent to participate Not applicable.
Consent for publication

Not applicable.

\section{Competing interests}

The authors declare that they have no competing interests.

\section{Publisher's Note}

Springer Nature remains neutral with regard to jurisdictional claims in published maps and institutional affiliations.

\section{Author details}

${ }^{1}$ Department of Pneumology, Institut Clinic de Respiratori, Hospital Clinic of Barcelona - Institut d'Investigacions Biomèdiques August Pi i Sunyer (IDIBAPS), University of Barcelona (UB) - SGR 911 - Ciber de Enfermedades Respiratorias (Ciberes, CB06/06/0028), Villarroel 170, 08036 Barcelona, Spain. ${ }^{2}$ Seccion Neumologia, Hospital Nacional Prof. Alejandro Posadas, Illia y Marconi s/n (1684), Palomar, Argentina. ${ }^{3}$ Pulmonary Division, Heart Institute, Hospital das Clínicas, University of São Paulo, Av. Dr. Arnaldo, 455-Cerqueira César - CEP: 01246903, São Paulo, Brazil.

Published online: 04 August 2017

\section{References}

1. World Health Organization. Global Action Plan on Antimicrobial Resistance. 2015. http://apps.who.int/iris/bitstream/10665/193736/1/9789241509763_ eng.pdf?ua $=1$. Accessed June 2017.

2. Lawes T, Lopez-Lozano JM, Nebot C, Macartney G, Subbarao-Sharma R, Dare CR, Edwards GF, Gould IM. Turning the tide or riding the waves? Impacts of antibiotic stewardship and infection control on MRSA strain dynamics in a Scottish region over 16 years: non-linear time series analysis. BMJ Open. 2015;5(3):e006596.

3. Karanika S, Paudel S, Grigoras C, Kalbasi A, Mylonakis E. Systematic review and meta-analysis of clinical and economic outcomes from the implementation of hospital-based antimicrobial stewardship programs. Antimicrob Agents Chemother. 2016;60(8):4840-52.

4. Luna CM, Aruj P, Niederman MS, Garzon J, Violi D, Prignoni A, Rios F, Baquero S, Gando S. Appropriateness and delay to initiate therapy in ventilator-associated pneumonia. Eur Respir J. 2006;27(1):158-64.

5. Leone M, Bechis C, Baumstarck K, Lefrant JY, Albanese J, Jaber S, Lepape A, Constantin JM, Papazian L, Bruder N, et al. De-escalation versus continuation of empirical antimicrobial treatment in severe sepsis: a multicenter nonblinded randomized noninferiority trial. Intensive Care Med. 2014;40(10): 1399-408.

6. Kalil AC, Metersky ML, Klompas M, Muscedere J, Sweeney DA, Palmer LB, Napolitano LM, O'Grady NP, Bartlett JG, Carratala J, et al. Management of adults with hospital-acquired and ventilator-associated pneumonia: 2016 clinical practice guidelines by the Infectious Diseases Society of America and the American Thoracic Society. Clin Infect Dis. 2016;63(5):e61-e111.

7. Ewig S, Welte T, Chastre J, Torres A. Rethinking the concepts of communityacquired and health-care-associated pneumonia. Lancet Infect Dis. 2010; 10(4):279-87.

8. Kett DH, Cano E, Quartin AA, Mangino JE, Zervos MJ, Peyrani P, Cely CM, Ford KD, Scerpella EG, Ramirez JA. Implementation of guidelines for management of possible multidrug-resistant pneumonia in intensive care: an observational, multicentre cohort study. Lancet Infect Dis. 2011;11(3): 181-9.

9. Torres A, Lee N, Cilloniz C, Vila J, Van der Eerden M. Laboratory diagnosis of pneumonia in the molecular age. Eur Respir J. 2016;48(6): 1764-78.

10. Opota O, Croxatto A, Prod'hom G, Greub G. Blood culture-based diagnosis of bacteraemia: state of the art. Clin Microbiol Infect. 2015; 21(4):313-22.

11. Garnier M, Rozencwajg S, Pham T, Vimont S, Blayau C, Hafiani M, Fulgencio $J P$, Bonnet F, Mainardi JL, Arlet $G$ et al. Evaluation of early antimicrobial therapy adaptation guided by the BetaLACTA Test: a case-control study. Crit Care. 2017;21(1):161

12. Dark P, Blackwood B, Gates S, McAuley D, Perkins GD, McMullan R, Wilson C, Graham D, Timms K, Warhurst G. Accuracy of LightCycler((R)) SeptiFast for the detection and identification of pathogens in the blood of patients with 
suspected sepsis: a systematic review and meta-analysis. Intensive Care Med. 2015;41(1):21-33

13. Gadsby NJ, Russell CD, McHugh MP, Mark H, Conway Morris A, Laurenson IF, Hill AT, Templeton KE. Comprehensive molecular testing for respiratory pathogens in community-acquired pneumonia. Clin Infect Dis. 2016;62(7):817-23.

14. Prina E, Ranzani OT, Torres A. Community-acquired pneumonia. Lancet. 2015;386(9998):1097-108 